\title{
Isopathic Remedy Prepared from Convalescent Plasma as a Therapeutic Option for COVID-19?
}

\author{
Suneel Prajapati ${ }^{1}$ \\ ${ }^{1}$ Drug Standardization Unit, Department of Microbiology \& Molecular \\ Biology, Dr. DP Rastogi Central Research Institute for Homeopathy, \\ Noida, Uttar Pradesh, India \\ Homeopathy 2020;109:184-185.
}

Address for correspondence Suneel Prajapati, MSc, PhD, Drug Standardization Unit, Department of Microbiology \& Molecular biology, Dr. DP Rastogi Central Research Institute for Homeopathy, A-1/1 Sector 24, Noida, Uttar Pradesh, India

(e-mail: saimpj@gmail.com).
Coronavirus disease 2019 (COVID-19) is a highly infectious illness that has continued to wreak havoc across the globe after its first appearance in Wuhan, China, in December 2019. ${ }^{1}$ Despite worldwide efforts to contain the ensuing pandemic, the virus SARS-CoV-19 has spread globally in the absence of any clinically proven prophylaxis or therapeutic strategy. ${ }^{2}$ Scientists are racing to develop effective drugs and vaccines for the new coronavirus, but none has been identified to date. One treatment option in current focus is convalescent plasma (CP) therapy. According to the World Health Organization (WHO), the experience in the past suggests that the empirical use of CP might be a potentially useful treatment for COVID-19. Recently published data show that passive immunization using a single dose $(200 \mathrm{~mL})$ of recovered patients' CP significantly increased the levels of antibodies, offering a high degree of protection. ${ }^{3,4}$ The plasma of recovered COVID-19 donors contains specific anti-SARS-CoV-19 IgG and IgM antibodies, which neutralize the virus. ${ }^{5-7}$ However, despite this advantage, some risk is also associated with CP therapy: in a study from Johns Hopkins University, immunologists cited risks such as inadvertent infection being transferred to the patient, possible failure of the therapy resulting in an enhanced form of the infection, or suppression of the body's natural immune response that leaves a COVID-19 patient vulnerable to subsequent re-infection. ${ }^{8}$ Thus, there could be additional advantages in a CP-based approach to COVID-19 that possesses fewer risks.

In view of the above, we propose the use of a homeopathic (highly diluted) potency of CP in the management of COVID-19. A person who has been sick with proven COVID-19 and recovers would have blood drawn and screened for virusneutralizing antibodies and it should be free from other infectious diseases, which could then be used to prepare an isopathic remedy as per recognized homeopathic pharmacopeias such as the Homoeopathic Pharmacopoeia of India, ${ }^{9}$

received

May 31, 2020

accepted after revision

June 1, 2020

published online

July 9,2020
Homeopathic Pharmacopeia of United States, ${ }^{10}$ and Brazilian Homeopathic Pharmacopeia. ${ }^{11}$ The scientific preparation of such an isopathic medicine and its administration would require a facility equipped to process plasma donations, serological assays to detect SARS-CoV-2, and virological assays to measure viral neutralization, as well as the ability to develop study protocols that could assess the efficacy of the proposed therapeutic intervention and measure the immune response. Alcohol-based high dilution and homeopathic dynamization would make them safe for oral use.

In the absence of an effective therapeutic strategy, thousands of people worldwide are dying every day because of COVID-19. Thus, we propose this alternative or complementary approach that would introduce virus neutralizing antibody from donors in the form of an isopathic preparation for patients with COVID-19. Antibody-based isopathy, using a medicinal preparation containing homeopathic dilutions $\left(<10^{-24} \mathrm{M}\right)$ of antibodies, has been used for the treatment of viral upper respiratory tract infections such as common cold, influenza, or influenza-like illnesses. ${ }^{12}$ Thus, such a remedy might have wide-ranging therapeutic opportunities against this new and devastating pandemic-at least until an effective conventional vaccine or treatment may become available for containing or limiting the disease. Another advantage of the proposal is that an isopathic medicine can be prepared in a very short time, and necessitating only a small amount of CP.

Conflict of Interest

None declared.

\section{References}

1 World Health Organization. Pneumonia of unknown cause-China. Available at: https://www.who.int/csr/don/05-january-2020-pneumonia-of-unkown-cause-china/en/. Accessed January 5, 2020
Copyright $\odot 2020$ The Faculty of Homeopathy
DOI https://doi.org/ 10.1055/s-0040-1714061. ISSN 1475-4916. 
2 Xu B, Gutierrez B, Mekaru S, et al. Epidemiological data from the COVID-19 outbreak, real-time case information. Sci Data 2020; 7:106

3 Duan K, Liu B, Li C, et al. Effectiveness of convalescent plasma therapy in severe COVID-19 patients. Proc Natl Acad Sci U S A 2020;117:9490-9496

4 Shen C, Wang Z, Zhao F, et al. Treatment of 5 critically ill patients with COVID-19 with convalescent plasma. JAMA 2020;323: 1582-1589

5 Marano G, Vaglio S, Pupella S, et al. Convalescent plasma: new evidence for an old therapeutic tool? Blood Transfus 2016; 14:152-157

6 Anudeep TC, Jeyaraman M, Shetty DU, et al. Convalescent plasma as a plausible therapeutic option in nCOVID-19-a review. J Clin Trials 2020;10:409
7 Chen L, Xiong J, Bao L, Shi Y. Convalescent plasma as a potential therapy for COVID-19. Lancet Infect Dis 2020;20:398-400

8 Bloch EM, Shoham S, Casadevall A, et al. Deployment of convalescent plasma for the prevention and treatment of COVID-19.J Clin Invest 2020;130:2757-2765

9 Homoeopathic Pharmacopoeia of India. 1st ed. 4thVol. New Delhi: Ministry of Health Government of India; 1983:136-137

10 The Homeopathic Pharmacopeia of United States (HPUS). Boston: Pharmacopeia Convention of the American Institute of Homeopathy; 2004

11 Brazilian Homeopathic Pharmacopoeia (Brz HP). 3rd ed. 2011

12 Martyushev-Poklad A, Bruhwyler J, Heijmans S, et al. Efficacy of a novel antibody TLR3 modulator in the self-treatment of common cold: the ESTUAR trial. Adv Infect Dis 2015;5:204-217 